\title{
Light Element Quantification in Irradiated Nanostructured Ferritic Alloys
}

\author{
M. K. Miller, ${ }^{1}$ Q. Li, ${ }^{1}$ B. Mazumder, ${ }^{1}$ and C. M. Parish ${ }^{2}$ \\ ${ }^{1}$ Center for Nanophase Materials Science, Oak Ridge National Laboratory, Oak, Ridge, TN \\ 37831-6139, USA \\ ${ }^{2}$ Materials Science and Technology Division, Oak Ridge National Laboratory, Oak, Ridge, TN \\ 37831-6064, USA
}

As the local electrode atom probe, and almost all previous generations of instruments, use a time-of-flight mass spectrometer, atom probe tomography (APT) is able to detect, and in most cases quantify, all elements. However, an appropriate pulse repetition rate for the field evaporation pulse, and the associated timing window, must be selected to detect the entire range of elements present. Hence, APT has always been a microanalytical technique for light element analysis and is routinely used for the analysis of $\mathrm{Li}, \mathrm{Be}, \mathrm{B}, \mathrm{C}, \mathrm{N}$, and $\mathrm{O}$ in a wide variety of materials. Thus, the focus of this paper is on APT analysis of $\mathrm{H}$ and $\mathrm{He}$ in materials.

In addition to producing displacement cascades and radiation damage, neutron irradiation initiates nuclear reactions, which lead to the transmutation of atoms, producing $\mathrm{He}$ and $\mathrm{H}$ gases. These reactions, which include neutron capture followed by $\alpha$-particle, i.e., ${ }_{4} \mathrm{He}^{2+}$, emission, $(n, \alpha)$, neutron capture, and proton, ${ }^{1} \mathrm{H}^{+}$, emission $(n, p)$. These gases produce swelling, and, at high doses, can lead to the formation of He bubbles, resulting in He embrittlement. The effects of this reaction and service at elevated temperatures can be simulated with the use of $4 \mathrm{He}$ implantation without the associated activity introduced by high dose neutron irradiation.

Although APT frequently uses standard or known composition alloys to establish the proper analysis parameters, such as specimen temperature, pulse fraction or laser energy, standing voltage, etc., for each material under investigation, the interpretation of the mass spectra for compositional information is a standardless method due to the built-in calibration from the use of the table of natural abundances of the isotopes for each element. However, both $\mathrm{H}$ and $\mathrm{He}$ introduce some additional factors that must be taken into account when interpreting mass spectra.

Hydrogen is normally observed in the mass spectra of most materials as mass peaks at $\mathrm{H}_{1}^{+}, \mathrm{H}_{2}{ }^{+}$, and $\mathrm{H}_{3}{ }^{+}$, at 1,2 , and $3 \mathrm{Da}$, respectively, as shown in the low mass region of the mass spectrum of a high-dose He-implanted nanostructured ferritic alloy in Fig. 1. Hydrogen is the main residual gas in the mass spectrometer at its normal operating pressure of between $10^{-10}$ and $10^{-8} \mathrm{~Pa}$, even though non-evaporator getter or titanium sublimation pumps, in combination with ion pumps, are used to evacuate the vacuum system. Due to the small size of the $\mathrm{H}$ atom, it can permeate through the stainless steel vacuum vessel. Therefore, hydrogen is adsorbed on the surface of the cryogenically cooled needle-shaped specimen and then diffuses to the apex region, where it field evaporates. Ideally, the use of much lower specimen temperatures, i.e. much less than the freezing point of $\mathrm{H}(14 \mathrm{~K}$ at 1 atmosphere), would be beneficial in trapping and freezing the $\mathrm{H}$ on the surface of the specimen to prevent surface diffusion. Because of this issue, $\mathrm{H}$ studies generally use deuterium rather than $\mathrm{H}$ to minimize the problem. The analysis of both $\mathrm{H}$ and $\mathrm{He}$ concentrations are also complicated by the formation of molecular ions, e.g., $\mathrm{H}$ and $\mathrm{He}$ have been detected as $\mathrm{MH}$ and $\mathrm{MHe}$ ions, where $\mathrm{M}$ is any atom. However, helides are rarely observed at the typical pressures used today, but were observed when 
the atom probe was operated at the much higher He pressures used for field ion microscopy, i.e., $\approx 10^{-3}$ $\mathrm{Pa}$. Although there is a potential isobar overlap between ${ }_{3} \mathrm{H}$ and ${ }_{3} \mathrm{He}$, the extremely low abundance of ${ }_{3} \mathrm{He}(0.00013 \%)$ and the use of ${ }_{4} \mathrm{He}$ in $\mathrm{He}$ ion implantations, or the production of ${ }_{4} \mathrm{He}$ during transmutation, effectively eliminates this concern.

The He in solid solution can be estimated from the mass spectra after accounting for the background noise. In this example of a 4He-irradiated injected to a concentration of $\sim 3$ at. $\%$ He in a 14 YWT nanostructured ferritic alloy after a post irradiation anneal of $10 \mathrm{~h}$ at $750{ }^{\circ} \mathrm{C}$ is shown in Fig. 1, where the He content in solid solution was estimated to be $75 \pm 7$ appm.[1] As He is almost insoluble in $\alpha-\mathrm{Fe}$, once the He solubility limit is reached, the excess He precipitates as small He bubbles. Helium escapes from the bubbles when they intersect the continuously field-evaporated surface and are lost to the vacuum system. Therefore, the He concentration in the bubbles cannot be measured. However, the location and size of the bubbles can be estimated from density isosurfaces of the remaining cavity.[2] The hydrogen trapping sites in a TiC precipitation-hardening steel [3] and titanium hydride precipitates have also been characterized by APT.[4,5]

\section{References:}

[1] Q. Li et al., J. Nucl. Mater., 445 (2014) p. 165.

[2] P. D. Edmondson et al., Scripta Mater., 65 (2011) p. 731.

[3] J. Takahashia et al., Scripta Mater., 63 (2010) p. 261.

[4] J. Takahashia et al., Ultramicrosc., 109 (2009) p. 568.

[5] Research sponsored by the Materials Sciences and Engineering Division, Office of Basic Energy Sciences, U.S. Department of Energy, and through a user project supported by ORNL's Center for Nanophase Materials Sciences (CNMS), which is sponsored by the Scientific User Facilities Division, Office of Basic Energy Sciences, U.S. Department of Energy.

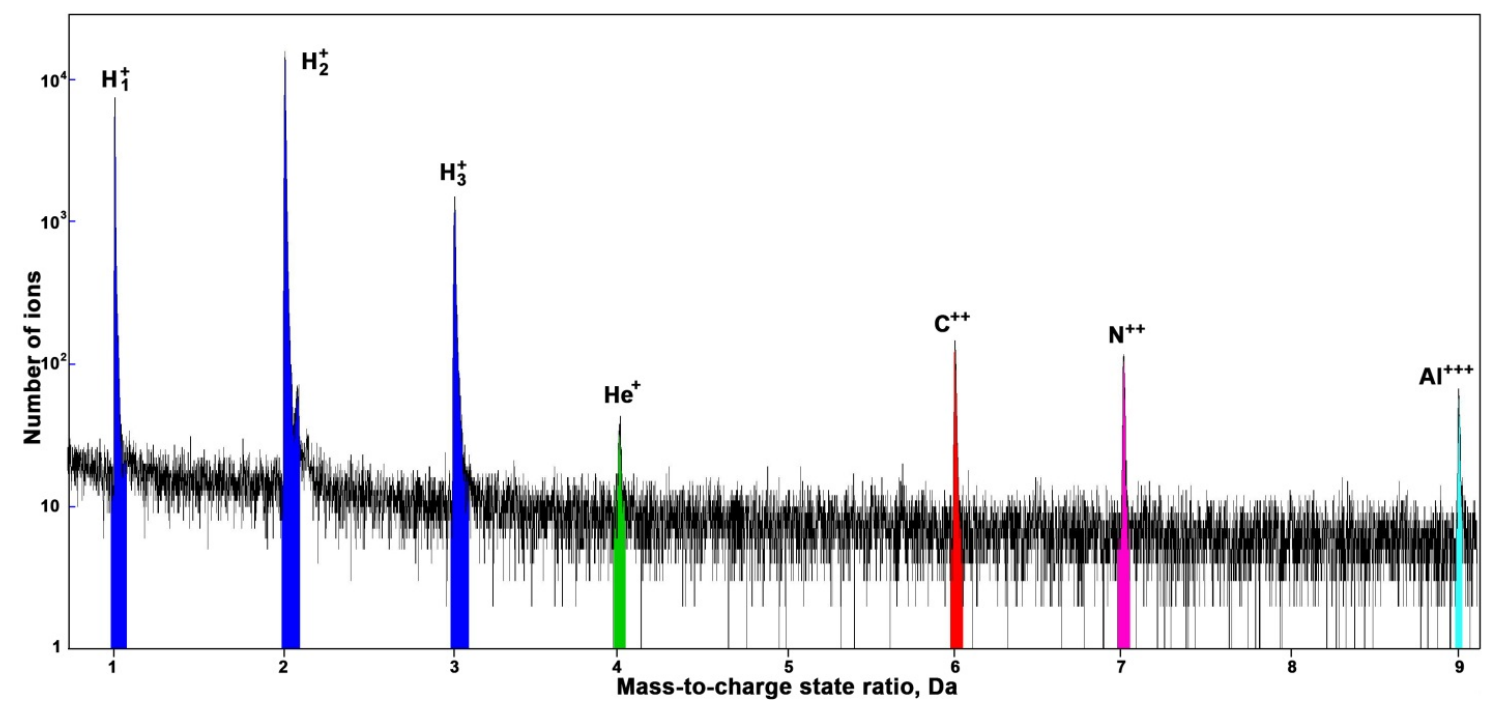

Figure 1. Low mass portion of the mass spectrum from a 14YWT nanostructured ferritic alloy that was He implanted normal to the surface with $335 \mathrm{keV}{ }_{4} \mathrm{He}^{+}$ions to a fluence of $6.8 \times 10^{20} \mathrm{He} \mathrm{m}^{-2}$ at a temperature of $400{ }^{\circ} \mathrm{C}$. The mass peaks for $\mathrm{H}_{1}^{+}, \mathrm{H}_{2}^{+}, \mathrm{H}_{3}^{+}$, and ${ }_{4} \mathrm{He}^{+}$at $1,2,3$, and $4 \mathrm{Da}$, respectively and other light elements $\mathrm{C}^{++}, \mathrm{N}^{++}$, and $\mathrm{Al}^{++}$are also indicated. 